\title{
Early Transfusion of Convalescent Plasma Improves the Clinical Outcome in Severe SARS-CoV2 Infection
}

\author{
Eszter Fodor (D) - Veronika Müller · Zsolt Iványi · Tímea Berki · \\ Olga Kuten Pella · István Hornyák · Mira Ambrus · Ágnes Sárkány · \\ Árpád Skázel · Ágnes Madár · Dorottya Kardos · Gábor Kemenesi · \\ Fanni Földes · Sándor Nagy · Andrea Matusovits · Nacsa János · \\ Attila Tordai · Ferenc Jakab · Zsombor Lacza
}

Received: May 27, 2021 / Accepted: July 26, 2021 / Published online: November 24, 2021

(C) The Author(s) 2021

\section{ABSTRACT}

Introduction: Plasma harvested from convalescent COVID-19 patients (CCP) has been applied as first-line therapy in the early phase of the SARS-CoV2 pandemic through clinical studies using various protocols.

Methods: We present data from a cohort of 267 hospitalized severe COVID-19 patients who

E. Fodor $(\bowtie) \cdot$ O. Kuten Pella $\cdot$ Z. Lacza

Orthosera Kft, Budapest 1149, Hungary

e-mail: eszter.fodor@orthosera.com

O. Kuten Pella

e-mail: olga.kuten@orthoser.com

V. Müller

Department of Pulmonology, Semmelweis

University, Budapest 1083, Hungary

e-mail: muller.veronika@med.semmelweis-univ.hu

Z. Iványi

Department of Anesthesiology and Intensive

Therapy, Semmelweis University, Budapest 1082,

Hungary

e-mail: ivanyizs@gmail.com

G. Kemenesi · F. Földes · F. Jakab

Szentágothai Research Center, National Laboratory

of Virology, Univesity of Pécs, Pécs 7622, Hungary

G. Kemenesi

e-mail: kemenesi.gabor@gmail.com

F. Földes

e-mail: fanni4444@gmail.com received CCP. No transfusion-related complications were reported, indicating the overall safety of CCP therapy.

Results: Patients who eventually died from COVID-19 received CCP significantly later (3.95 versus 5.22 days after hospital admission) and had higher interleukin 6 (IL-6) levels $(28.9$ pg/ $\mathrm{ml}$ versus $102.5 \mathrm{pg} / \mathrm{ml}$ ) than those who survived. In addition, CCP transfusion caused a significant reduction in the overall

\section{F. Jakab}

e-mail: jakab.ferenc@pte.hu

Á. Sárkány · Á. Skázel

Szent György University Teaching Hospital, Székesfehérvár 8000, Hungary

\section{Á. Sárkány}

e-mail: skazelarpad@gmail.com

\section{Á. Skázel}

e-mail: asarkany1@gmail.com

S. Nagy · A. Matusovits · N. János

Hungarian National Blood Transfusion Service, Budapest 1113, Hungary

S. Nagy

e-mail: nagy.sandor@ovsz.hu

\section{A. Matusovits}

e-mail: foigazgato@ovsz.hu

N. János

e-mail: nacsa.janos@ovsz.hu 
inflammatory status of the patients regardless of the severity of disease or outcome, as evidenced by decreasing C-reactive protein, IL6 and ferritin levels.

Conclusion: We conclude that CCP transfusion is a safe and effective supplementary treatment modality for hospitalized COVID-19 patients characterized by better expected outcome if applied as early as possible. We also observed that IL- 6 may be a suitable laboratory parameter for patient selection and monitoring of CCP therapy effectiveness.

Keywords: Convalescent plasma; COVID-19; Interleukin-6; SARS2-CoV

\section{Key Summary Points}

\section{Why carry out this study?}

Plasma harvested from convalescent COVID-19 patients (CCP) has been applied as first-line therapy in the early phase of the SARS-CoV2 pandemic through clinical studies using various protocols. We present data from a cohort of 267 hospitalized severe COVID-19 patients who received CCP. Our hypothesis was that the clinical outcome will improve in those patients who receive convalescent plasma within 3 days of hospital stay

\section{Z. Lacza}

Department of Translational Medicine, Semmelweis

University, 1085 Budapest, Hungary

E. Fodor · M. Ambrus · Á. Madár · Z. Lacza

Univesity of Physical Education, Budapest 1223,

Hungary

M. Ambrus

e-mail: ambrus.mira@tf.hu

Á. Madár

e-mail: agnes.madar@orthosera.com

Z. Lacza

e-mail: zsombor.lacza@orthosera.com

A. Tordai

Department of Transfusiology, Semmelweis

\section{What was learned from the study?}

No transfusion-related complications were reported, indicating the overall safety of CCP therapy. Patients who eventually died from COVID-19 received CCP significantly later (3.95 versus 5.22 days after hospital admission) and had higher interleukin 6 (IL-6) levels $(28.9 \mathrm{pg} / \mathrm{ml}$ versus $102.5 \mathrm{pg} / \mathrm{ml}$ ) than those who survived. C-reactive protein (CRP) levels significantly decreased only 1 day after CCP transfusion (pre-transfusion

$111.5 \pm 73.45$; post-transfusion: $86.25 \pm 65.5 ; P=0.0008$ )

In addition, CCP transfusion caused a significant reduction in the overall inflammatory status of the patients regardless of the severity of disease or outcome, as evidenced by decreasing C-reactive protein, IL6 and ferritin levels. We conclude that CCP transfusion is a safe and effective supplementary treatment modality for hospitalized COVID-19 patients characterized by better expected outcome if applied as early as possible. We also observed that IL-6 may be a suitable laboratory parameter for patient selection and monitoring of CCP therapy effectiveness

University, Budapest 1089, Hungary

e-mail: tordai.attila@med.semmelweis-univ.hu

T. Berki

Department of Immunology and Biotechnology, University of Pécs, Budapest 7643, Hungary e-mail: berki.timea@pte.hu

D. Kardos

Research Center Natural Sciences, Budapest 1117, Hungary

e-mail: dorottya333@gmail.com

I. Hornyák

Instute of Translational Medicine, Semmelweis University, Budapest, Hungary 


\section{INTRODUCTION}

Severe acute respiratory syndrome caused by the novel coronavirus SARS-CoV2 has been responsible for an unprecedented world pandemic starting in Wuhan, China, in January 2020. This represented an extraordinary challenge for the health care systems and entire societies of the developed countries $[1,2]$ including Hungary [3]. SARS-CoV2-induced COVID-19 disease is characterized by acute viral pneumonia associated with progressive respiratory insufficiency, requiring oxygen supplementation in about $15 \%$ and mechanical ventilation in $5 \%$ of the cases with reported overall mortality rates of $2.3 \%[4,5]$. Since SARS-CoV2 is a new human pathogen, initially neither vaccines nor effective therapeutic modalities were available. With several earlier attempts of antiviral passive immunotherapy, COVID-19 convalescent plasma (CCP) therapy has quickly become a readily available and promising therapeutic modality against severe COVID-19 [6, 7]. Given the large amount of clinical experience with allogeneic plasma transfusions and the relative lack of potential side effects, regulatory agencies have quickly granted permissions for several parallel clinical trials with CCP [8-10]. After CCP transfusion, virus neutralization antibodies represent the most important mode of action but moderating the unnecessarily severe immune reaction by several soluble factors has also been proposed [11-13].

Apart from the multitude of case studies, initial reports of CCP clinical studies on sizeable cohorts have not been able to demonstrate significant improvements in mortality rates [14-17]. In contrast, in subsequent studies, mortality benefits were documented among unselected severe COVID-19 patients after CCP transfusions in the USA [18-21], China [22, 23], India [24] and Europe [25, 26] and among selected patients based on risk factors [27, 28]. In addition, a potential benefit was also observed in a meta-analysis [29]. Development of severe COVID-19-associated respiratory disease was significantly less frequent after CCP transfusion administered within $72 \mathrm{~h}$ of onset of mild COVID-19 infection compared to a randomized control group [30]. In an early meta-analysis, low to moderate evidence indicated a lacking benefit [31]; a later systematic compilation covering $>35,000$ CCP-treated cases indicated a significantly reduced odds ratio for all-cause mortality associated with CCP transfusion [29]. Thus, outcome observations after CCP therapies are controversial because of the difficulties to form and analyze homogeneous patient cohorts and control groups, the diverse availability of other therapeutic modalities and the substantial differences in local clinical practices. Most studies aimed at reducing mortality rates; however, this required many recruited patients and homogeneous treatment groups, which was seldom the case. However, quantitative laboratory parameters may serve as secondary endpoints and provide information on individual patients and also on potential patient selection criteria for future studies. Our earlier experience with blood plasma-based therapies has also provided evidence that measuring cytokine levels may be informative in monitoring the effectiveness of blood-based therapies $[13,32]$. Thus, the aim of the current study was to analyze the outcome and immunology parameters after CCP transfusions in severe COVID-19 patients.

\section{METHODS}

\section{Study Description}

The trial was designed in accordance with $\mathrm{WHO}$ (2015 WHO/HIS/KER/GHE/15.1) as an open-label, prospective interventional study and approved by the Hungarian National Medical Research Council (approval number: IV/3457/22020-EKU) and registered in ClinicalTrials.gov (NCT04345679). Due to ethical concerns of leaving any patient untreated or placebo-treated (e.g., non-convalescent fresh frozen plasma), no control arm was included. The primary clinical endpoint was patient survival; secondary endpoints were the time of convalescent plasma administration (days from hospital admission), duration of hospital stay (days), mortality rate (\% of patients), hematological laboratory 
parameter WBC and inflammatory markers such as ferritin, C-reactive protein (CRP) and interleukin-6 (IL-6).

\section{Plasma Donation}

Plasma was collected from healthy voluntary convalescent donors of both sexes aged 18-65 years, with confirmed previous SARS-CoV2 infection. A positive result of either SARS-CoV2 PCR or antigen screening test at the time of plasma donation was a reason for exclusion. Donors were required to meet all eligibility requirements valid for regular blood donors. An inclusion criterion was a positive IgG antibody level $(>24 \mathrm{U} / \mathrm{ml})$ against SARS-CoV2 nucleocapsid protein (measured by Microgen semiquantitative ELISA assays). The mean value of the nucleocapsid IgG levels from our first 444 donors is $72.743 \pm 36.59 \mathrm{U} / \mathrm{ml}$. Although the range is quite wide, most therapeutically applied plasma units were in a medium strength range and only a few had extremely high antibody levels. To decrease the risks of transfusionrelated acute lung injury (TRALI), all female donors were screened for anti-HLA antibodies, and positive donors were excluded from plasma donation. Altogether $400 \mathrm{ml}$ of convalescent plasma was collected from donors through an automated plasma apheresis separator. The Hungarian National Blood Service divided the $400 \mathrm{ml}$ plasma into two therapeutic doses of $200 \mathrm{ml}$. Plasma products underwent pathogen reduction and irradiation. The processed plasma was stored at $-20^{\circ} \mathrm{C}$ until used. $\mathrm{ABO}$ compatibility was strictly observed throughout the study.

\section{Recipients}

Convalescent plasma recipients were hospitalized patients of both sexes and ages admitted to a university hospital COVID ward between April 2020 and February 2021 and who were suitable for receiving plasma judged by their attending physicians. At the start of the current study no clear guidelines were available for CCP prescription, so the clinical decision was based on the two preliminary reports from China where CCP therapy was applied in the early phase of the pandemic $[1,4]$. Since these studies involved patients of severe COVID with extensive need for breathing support, CCP was applied in patients with later-stage disease without any strictly defined criteria-as was the standard of care elsewhere at the time [29]. Indeed, the main goal of the current study was to define the prescription guideline for attending clinicians to optimize the use of this therapeutic option in a Central European population.

\section{Laboratory Measurements}

Laboratory hematological parameters were measured with clinical hematology analyzers. Ferritin and C-reactive protein levels were measured before and on days 1 and 7 after plasma transfusion. White blood cell count was determined before and on days 1 and 2 after plasma transfusion. Levels of the proinflammatory cytokine interleukin-6 (IL-6) were measured before and on days 1 and 7 with electrochemiluminescence immunoassay (ECLIA).

\section{Simple Plex Cytokine Assay}

IL-1 beta, IL-6, IL-8 and TNF alpha concentrations were analyzed in plasma from 21 selected COVID-19 patients with Simple Plex assays run on the Ella ${ }^{\mathrm{TM}}$ automated immunoassay analyzer (ProteinSimple, San Jose, CA). Diluted (1:2) plasma samples together with buffer were loaded into the ELLA cartridge and measured according to the manufacturer's instruction. Patients selected for Simple Plex Cytokine measurements were a representative subset of the study population (ICU patients, $n=6$, mean WHO ordinal severity scale $6.833 \pm 0.1667$ ), COVID ward patients $(n=15$, mean WHO ordinal severity scale $3.533 \pm 0.133$ ).

\section{Statistical Analysis}

Data were analyzed with the two-tailed MannWhitney test and Fisher's exact test using GraphPad Prism software. $P<0.05$ was considered significant. 
Table 1 (A) Baseline characteristics of COVID-19 positive patients selected for CCP therapy. (B) WHO ordinal severity scale in the COVID ward and ICU

\begin{tabular}{|c|c|c|c|c|}
\hline & $\begin{array}{l}\text { All patients }(n= \\
267)\end{array}$ & $\begin{array}{l}\text { COVID ward }(n= \\
\text { 202) }\end{array}$ & $\begin{array}{l}\text { ICU }(n= \\
65)\end{array}$ & $\begin{array}{l}p(<0.05 \\
\text { significant })\end{array}$ \\
\hline \multicolumn{5}{|l|}{ (A) } \\
\hline Age (years, median) & 67 & 69 & 63 & 0.0103 \\
\hline \multirow[t]{2}{*}{ Sex, $n(\%)$} & Female $40 \%$ & Female $45 \%$ & $\begin{array}{c}\text { Female } \\
26 \%\end{array}$ & 0.0089 \\
\hline & Male $60 \%$ & Male $55 \%$ & Male $74 \%$ & \\
\hline Hospitalization time (days, median) & 15 & 14 & 17 & 0.0202 \\
\hline Time until CCP therapy (days, median) & 3 & 3 & 3 & $0.8087, \mathrm{~ns}$ \\
\hline Hypertension, $n$ (\%) & $63.5 \%$ & $49.5 \%$ & $49 \%$ & $0.2959, \mathrm{~ns}$ \\
\hline Diabetes, $n$ (\%) & $25.5 \%$ & $22.3 \%$ & $12 \%$ & $0.1833, \mathrm{~ns}$ \\
\hline Cancer active, $n(\%)$ & $11.5 \%$ & $10.4 \%$ & $5.3 \%$ & $0.3014, \mathrm{~ns}$ \\
\hline Other chronic illness & $21.2 \%$ & $10.5 \%$ & $6.1 \%$ & $0.4626, \mathrm{~ns}$ \\
\hline No chronic illness & $9.1 \%$ & $7.4 \%$ & $6.1 \%$ & $1, \mathrm{~ns}$ \\
\hline $\begin{array}{l}\text { Not known (no documentation about } \\
\text { chronic illness) }\end{array}$ & $22.1 \%$ & $19 \%$ & $29 \%$ & - \\
\hline Recovered, $n(\%)$ & $68.5 \%$ & $77.7 \%$ & $40 \%$ & $p<0.0001$ \\
\hline Deceased, $n(\%)$ & $31.5 \%$ & $22.3 \%$ & $60 \%$ & \\
\hline WBC $(\mathrm{G} / \mathrm{l})$, mean (day 1$)$ & 9.8 & 8.7 & 13.4 & 0.0010 \\
\hline Ferritin (ng/ml), mean (day 1$)$ & 1296 & 1026 & 2121 & 0.0003 \\
\hline CRP (mg/l), mean (day 1) & 111.5 & 103.7 & 136.6 & 0.0090 \\
\hline IL-6 (pg/ml), mean (day 1$)$ & 77.5 & 82.68 & 34.06 & $0.1452, \mathrm{~ns}$ \\
\hline WHO ordinal severity scale & 4.58 & 3.87 & 6.66 & $p<0.0001$ \\
\hline
\end{tabular}

\section{WHO ordinal severity scale}

\begin{tabular}{lllllllll}
\hline 0 & 1 & 2 & 3 & 4 & 5 & 6 & 7 & 8
\end{tabular}

(B)

COVID ward (number of patients)

$27 \quad 174 \quad 1$

ICU (number of patients)

22

43

Patients' parameters have been calculated for the whole group $(n=267)$ and for COVID ward and ICU patients. Data were analyzed with Fisher's exact test 

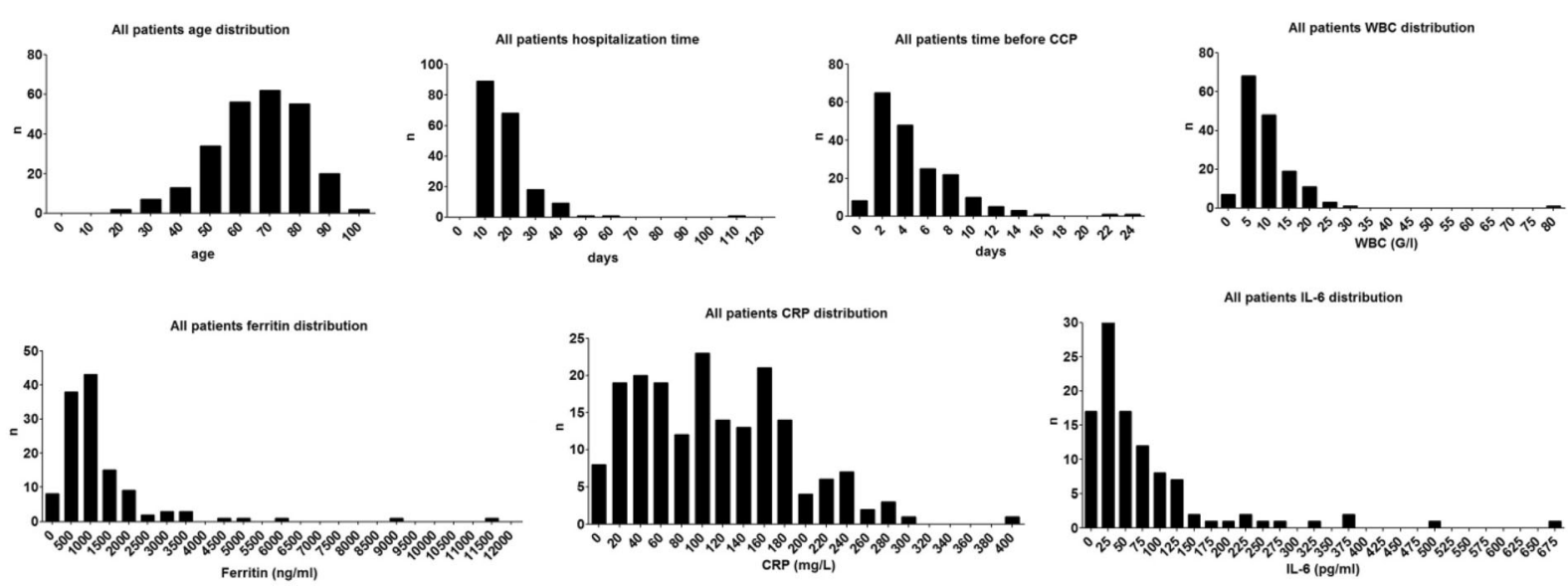

Fig. 1 Histograms presenting the distribution of age, hospitalization time, time before CCP and levels of WBC, ferritin, CRP and IL- 6 on day 1 . The total number of patients analyzed was 267; however, when laboratory tests were not performed on a given day, data were excluded.

\section{Statement of Ethics Compliance}

The study was conducted according to the guidelines of the Declaration of Helsinki and approved by the Hungarian National Ethics Committee (protocol code 1943-6/2020/EÜIG and date of approval: 2020.04.15). Informed consent was obtained from all subjects involved in the study.

\section{RESULTS}

\section{Patient Characteristics}

The key characteristics and laboratory findings of 267 patients can be found in Table 1. Data distribution was spread on a wide scale, demonstrated in histograms in Fig. 1 . The median patient age was 67 years, with a median hospitalization time of 15 days. Over $90 \%$ of patients had serious comorbidities and had
Documentation about WBC level was available for $n=158$ patients, about ferritin for $n=126$ patients, about CRP for $n=187$ patients and about IL- 6 for $n=104$ patients. Nonetheless, all statistical comparisons were adequately powered

markedly elevated inflammatory parameters before CCP treatment (Table 1). Seventy-six percent of patients were admitted to the COVID ward (CW) and $24 \%$ to the ICU.

After comparing patients from CW and ICU a statistical relationship among age, sex, hospitalization time, mortality, WBC, ferritin and CRP level was found. The median age of patients admitted to the ICU was lower (63 years) than that of CW patients (69 years), and $74 \%$ of ICU patients were male. As expected, WBC, ferritin and CRP levels on the day of admission were significantly higher in the ICU patient group. Also, ICU patients had longer hospitalization time but the median number of days to CCP therapy was the same in both groups. No significant association with $\mathrm{CW} / \mathrm{ICU}$ admission and the time until CCP therapy, chronic illness and IL-6 level was observed. Since the decision on whether a patient is treated at the ICU was based on multiple factors partly unrelated to their COVID-19 status, e.g.,

Table 2 WHO ordinal severity scale of the study participants

\begin{tabular}{llll}
\hline & $<\mathbf{3}$ days to CCP transfusion & $>\mathbf{3}$ days to CCP transfusion & $\boldsymbol{P}(<0.005)$ significant \\
\hline WHO ordinal severity scale & $4.529 \pm 1.247$ & $4.534 \pm 1.252$ & $\mathrm{~ns}(P=0.452)$ \\
\hline
\end{tabular}

Data are presented as means $\pm \mathrm{SD}$ 

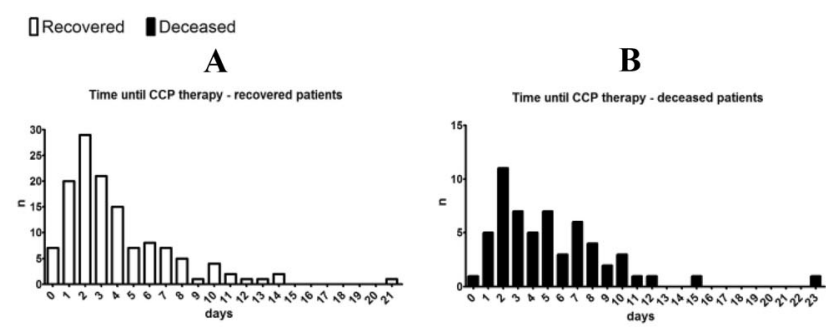

Fig. 2 Time until CCP therapy in hospitalized patients. $\mathbf{A}$ and $\mathbf{B}$ Histograms of time until CCP therapy in days from hospitalization in surviving and deceased patients, respectively. C Mean \pm SEM values of hospitalization time before CCP for recovered and deceased patients; asterisk indicates $P<0.05$ with Mann-Whitney test.

comorbidities or place availability, and there was no difference in the treatment regimens regarding plasma therapy or the inflammatory parameters between the CW and the ICU subgroups, the subsequent analyses are presented as a single group of patients.

There was no significant difference between the two groups, i.e., those who received plasma before 3 days were at the same average severity of COVID disease as those who received plasma at a later time point (Table 2).

\section{Administration of CCP to COVID Patients}

CCP transfusion was safe with no transfusionrelated adverse events reported in the entire study. CRP levels significantly decreased only 1 day after CCP transfusion (pre-transfusion $111.5 \pm 73.45 ; \quad$ post-transfusion: $\quad 86.2$ $5 \pm 65.5 ; P=0.0008$ ). To identify the best time point when CCP should be administered, the hospitalization time before CCP therapy was compared between the deceased and recovered patients (Fig. 2). Frequency distribution analysis revealed that CCP therapy was applied earlier in patients who eventually recovered than in those who died, with a significant difference $(P=0.0133)$ between the time of CCP therapy between the survivors (395 days) and deceased patients (522 days) (Fig. 2). Based on this observation, we regrouped the patients to those who received CCP up to 3 days after hospitalization and compared their survival rate to those that received CCP at day 4 or later time
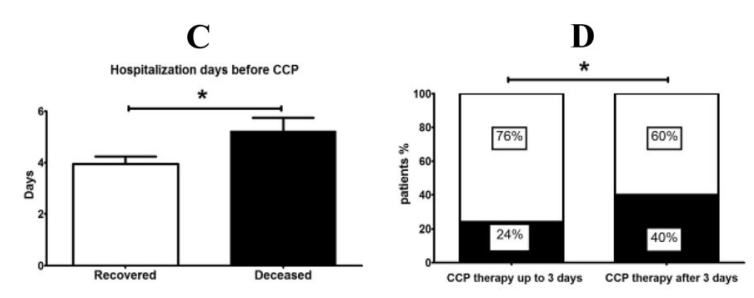

D Patients who received plasma during the first 3 days of hospitalization had a significantly better survival rate than those who received CCP therapy at later time points; asterisk indicates $P<0.05$ with Fisher's exact test

points in their respective treatment regimes. Indeed, the mortality rate was significantly lower $(P=0.0226)$ among patients who received CCP up to 3 days after hospital admission (24\%) versus patients who received it later (40\%) (Fig. 2).

\section{Effect of CCP Therapy on Inflammatory Parameters}

To identify the reliable prognostic factors for COVID patient's recovery, IL-6, IL-1 beta, IL-8 and TNF alpha were additionally analyzed from the available frozen serum samples of 21 patients (Fig. 3). IL-1 beta (deceased $0.5 \mathrm{pg} / \mathrm{ml}$, recovered $0.6 \mathrm{pg} / \mathrm{ml}$ ), IL-8 (deceased $31.3 \mathrm{pg} / \mathrm{ml}$, recovered $22.5 \mathrm{pg} / \mathrm{ml}$ ) and TNF alpha concentration (deceased $21.1 \mathrm{pg} / \mathrm{ml}$, recovered $16.1 \mathrm{pg} /$ $\mathrm{ml}$ ) were not above the physiological level (minimum-maximum values of cytokine levels in healthy controls according to the literature are $0.0-5.0 \mathrm{pg} / \mathrm{ml}$ for IL-1 beta [33], $0.0-50.4 \mathrm{pg} /$ $\mathrm{ml}$ for IL-8 [34] and $0.0-32.5 \mathrm{pg} / \mathrm{ml}$ for TNF alpha [34]). Also, the changes of these cytokine levels were not significant between recovered and deceased patients (Fig. 3). At the same time, IL-6 concentration was clearly above the normal level for healthy individuals $(0.0-12.7 \mathrm{pg} / \mathrm{ml}$ [34]) before plasma therapy and patients who died during hospitalization had significantly higher $(P=0.0066)$ IL-6 levels than survivors (deceased $102.5 \mathrm{pg} / \mathrm{ml}$, recovered $28.9 \mathrm{pg} / \mathrm{ml}$, Fig. 3). 
IL-1 beta

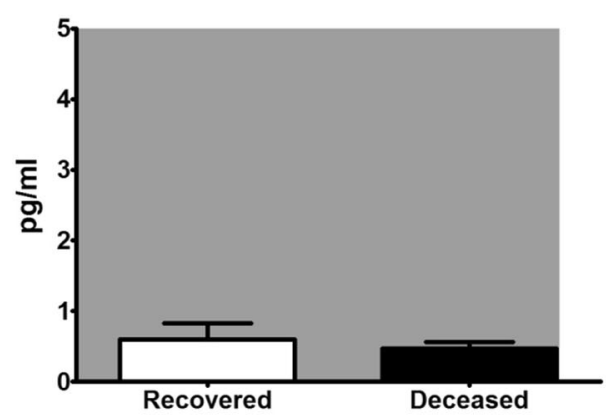

IL-8

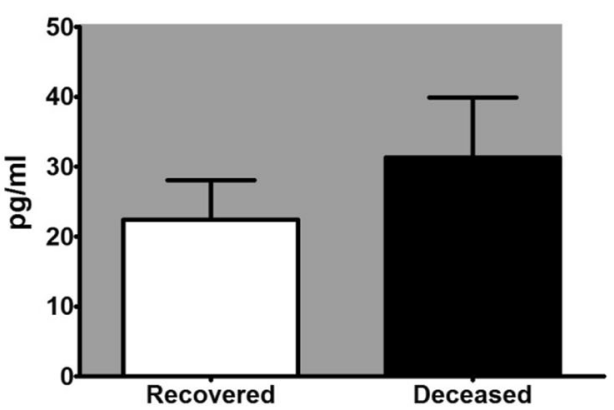

Fig. 3 IL-6, IL-1 beta, IL-8 and TNF alpha levels in survivors and decedents blood harvested before CCP therapy ( $n=21$ patients). Normal range is indicated with

The level of ferritin, CRP and IL- 6 was compared between blood samples collected before and after CCP therapy to assess if there was an improvement of patients' condition. All three parameters were significantly lower (ferritin $P=0.0025$; CRP and IL-6 $P<0.0001)$ after plasma administration (Fig. 4).

\section{DISCUSSION}

In the current study, we systematically monitored selected outcome parameters in a sizeable cohort of severe COVID-19 patients who received CCP therapy as a supplementary intervention besides standard supportive and causative therapies. As expected, several baseline characteristics showed significant differences upon comparing those patients who were treated on the COVID ward versus those under
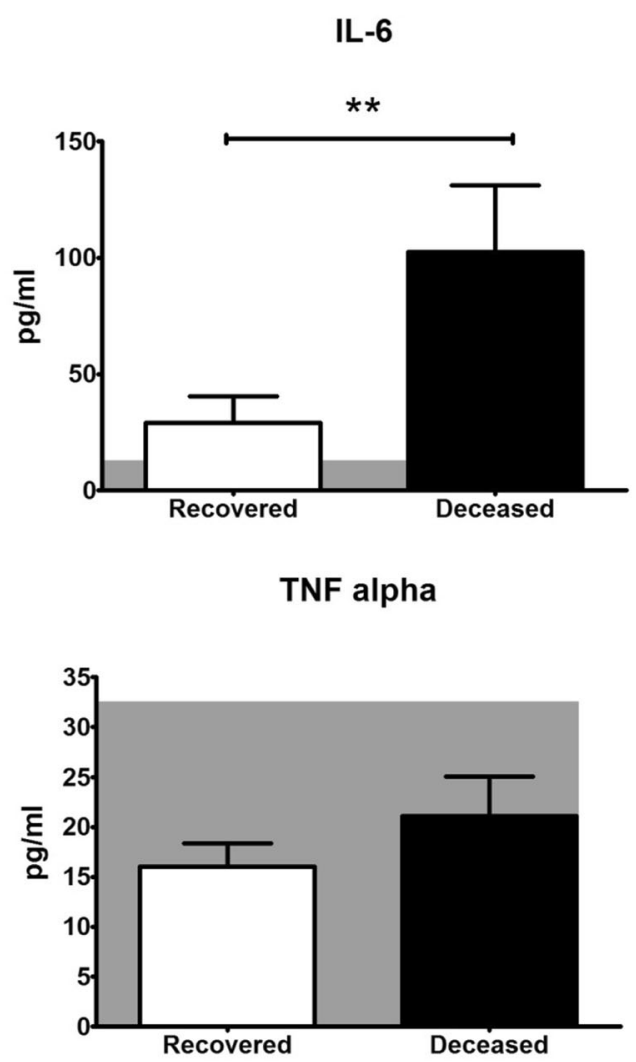

a gray area on each panel. Data are represented as average \pm SEM; asterisk indicates $P<0.05$ with MannWhitney test

intensive care reflecting the different severity of their overall clinical status. In agreement with other reports [24], males were over-represented in the ICU subgroup, along with elevated WBC, ferritin and CRP levels. A high proportion of patients had severe comorbidities that clearly affected their treatment needs in addition to their COVID19 status; therefore, it was not justified to separate the cohort into subgroups based on any variable singled out from a multitude of parameters.

We addressed the importance of initiation time point of CCP transfusions by using the indicator of number of days elapsing in the hospital prior to CCP therapy. In this comparison, significantly more time elapsed in the deceased subgroup compared to survivors. Moreover, dichotomizing the entire patient group according to the median value of days until CCP therapy with 3 days as a threshold 

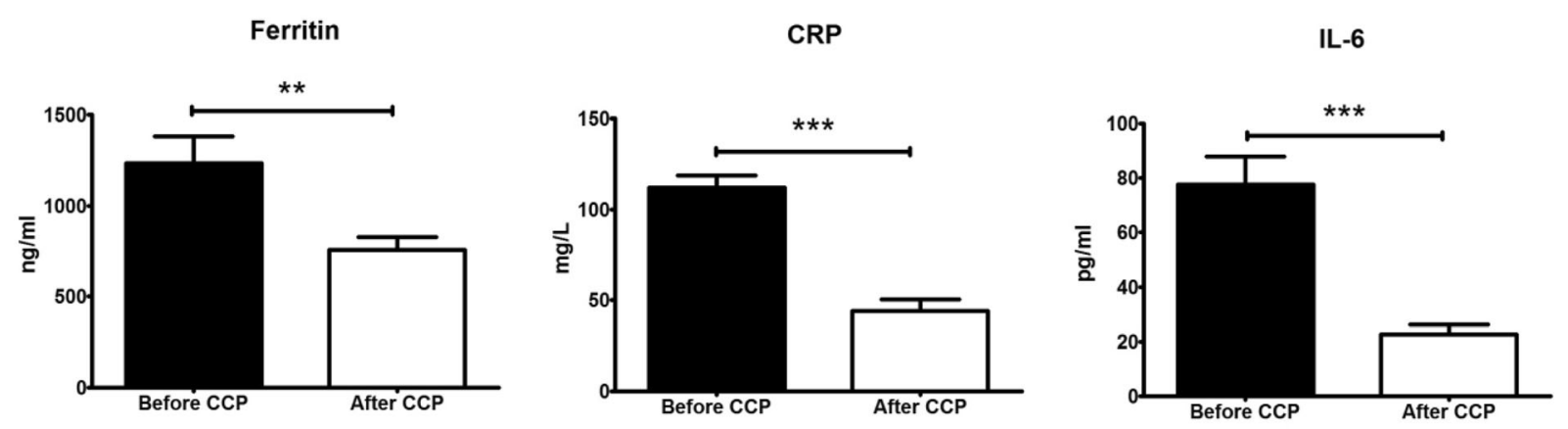

Fig. 4 IL-6, CRP and ferritin levels before and after CCP. Documentation of the ferritin level before and after CCP was available for $n=79$ patients, of CRP for $n=130$

showed a significantly higher proportion of deceased patients in the subgroup characterized by longer than 3 days. Support for the importance of early application of CCP therapy comes from a prospective USA study indicating significant mortality reduction compared to matched control cases only in the subgroup receiving CCP transfusion within $72 \mathrm{~h}$ of hospital admission [20]. In a smaller comparative study, CCP transfusion within $72 \mathrm{~h}$ of hospital admission was more efficient among patients aged $<65$ years [19]. In another smaller study a similar benefit of earlier application of CCP therapy was observed with improvements of several clinical outcomes associated with CCP administration before 7 days from diagnosis [26]. Furthermore, in an outstanding randomized, double-blind, placebo-controlled trial performed in Argentina, development of COVID19-associated predefined severe respiratory disease was significantly less frequent in the treated group receiving CCP transfusion within $72 \mathrm{~h}$ from the onset of mild COVID-19 in an elderly population [30]. The importance of appropriate timing of CCP transfusions as well as careful candidate selection instead of the compassionate use of CCP has clearly been emphasized in an editorial [35].

Considering the relative paucity of information on inflammatory cytokine levels in CCPtreated COVID-19-patients, in a subgroup of our cohort, we included baseline and follow-up measurements of critical cytokine levels such as IL-6, IL-8, TNF-alpha and IL-1-beta. Comparing patients and IL- 6 for $n=58$ patients. Data are presented as average \pm SEM; ${ }^{* *} P<0.01,{ }^{* * *} P<0.001$ with MannWhitney test

baseline levels between recovered and deceased patients, we observed that IL-6 was the only inflammatory cytokine characterized by significantly elevated baseline levels among the deceased CCP-treated patients, indicating a potential role of this inflammatory cytokine as a prognostic marker. In another comparison addressing marker status before and after CCP transfusion, similarly to general inflammatory markers, IL-6 levels showed significant decreases. This observation is in line with those of others and suggests a putative immunomodulatory effect exerted by ССР [11]. In particular, in a smaller study, besides IL-6, TNF-alpha and IFN-gamma levels also showed significant decreases while that of IL-10 increased following CCP therapy [36]. In the framework of another randomized trial of CCP therapy, Il-6 serum levels decreased along with those of interferon gamma-induced protein 10 in response to CCP transfusion [37]. However, it should be noted that the possible connection of IL-6 levels with the therapeutic effect of CCP does not mean a causal relationship either way, and further studies are needed to identify the molecular-level interactions between IL-6-involving inflammatory mechanisms. Notably, convalescent plasma is also a source of a number of interleukins and cytokines that are administered alongside the anti-SARS2-CoV neutralizing antibodies.

Limitations of the current study include its non-controlled design, its limited sample size and partial unavailability of samples for detailed 
immunological testing in a significant proportion of the patients included. Pre-hospital history of the patients was not accessible, leaving room for variation in SARS2-CoV2 infection periods. Considering all the above limitations, we believe that our observations should rather be viewed as an indicator prompting further studies with improved design targeting special features of CCP therapy such as early intervention in patients with only moderate IL-6 levels. Comparing results of the large number of registered clinical trials $(n=164$ on ClinicalTrials.gov at the time of writing) may help to identify critical factors in study design and patient selection to obtain benefits of clinical outcome after CCP in severe COVID-19; however, this future effort will depend on original study data becoming available.

\section{CONCLUSIONS}

In conclusion, our results indicate that CCP transfusion is a safe supplementary option that can easily be incorporated into the complex therapeutic scheme of severe COVID-19 patients. Early timing of CCP transfusion is clearly preferable. CCP transfusion resulted in significant decreases in inflammatory markers, and pretransfusion measurements of these markers may allow further stratification of severe COVID-19 patients amenable for efficient CCP therapy.

\section{ACKNOWLEDGEMENTS}

This work was partially supported by the Higher Education Institutional Excellence Program (FIKP) of the Ministry for Innovation and Technology, within the framework of the Molecular Biology thematic program of Semmelweis University as well as by grants from the National Research, Development and Innovation Fund (NKFI) K135757 and 2020-1.1.6JÖVÖ-2021-00010. We thank all the donors who donated convalescent plasma and all the nurses, doctors and health care workers who made this treatment possible.
Funding. This research, including the Journal's Rapid Service fees, was funded by the Ministry for Innovation and Technology. The grant numbers are the following: K135757 and 2020-1.1.6-JÖVÖ-2021-00010.4

Authorship. All named authors meet the International Committee of Medical Journal Editors (ICMJE) criteria for authorship for this article, take responsibility for the integrity of the work as a whole, and have given their approval for this version to be published.

Author Contributions. Conceptualization, Zsombor Lacza and Eszter Fodor and Olga Kuten.; methodology, Veronika Müller, validation, Ferenc Jakab, Gábor Kemenesi, Fanni Földes, István Hornyák; formal analysis, Ágnes Madár, Mira Ambrus, Dorottya Kardos, István Hornyák; investigation, Zsolt Iványi.; data curation, Eszter Fodor and Attila Tordai, János Nacsa; writing- original draft preparation, Zsombor Lacza, Olga Kuten; writing-review and editing, supervision, Attila Tordai, Zsombor Lacza, Eszter Fodor, Tímea Berki; project administration, Árpád Skázel, resources, Sándor Nagy, Andrea Matusovits, Ágnes Sárkány.

Disclosures. Eszter Fodor, Veronika Müller, Zsolt Iványi, Tímea Berki, Olga Kuten, István Hornyák, Mira Ambrus, Ágnes Sárkány, Árpád Skázel, Ágnes Madár, Dorottya Kardos, Gábor Kemenesi, Fanni Földes, Sándor Nagy, Andrea Matusovits, János Nacsa, Attila, Tordai and Ferenc Jakab confirm that they have nothing to declare. Zsombor Lacza owns stock in OrthoSera $\mathrm{kft}$, a startup company developing the hyperacute serum technology towards clinical application. All authors declare that there is no financial interests related to the material in the manuscript.

Compliance with Ethics Guidelines. The study was conducted according to the guidelines of the Declaration of Helsinki and approved by the Hungarian National Ethics Comittee (protocol code 1943-6/2020/EÜIG and date of approval: 2020.04.15). Informed consent was obtained from all subjects involved in the study. 
Data Availability. The datasets generated during and/or analyzed during the current study are available from the corresponding author on reasonable request.

Open Access. This article is licensed under a Creative Commons Attribution-NonCommercial 4.0 International License, which permits any non-commercial use, sharing, adaptation, distribution and reproduction in any medium or format, as long as you give appropriate credit to the original author(s) and the source, provide a link to the Creative Commons licence, and indicate if changes were made. The images or other third party material in this article are included in the article's Creative Commons licence, unless indicated otherwise in a credit line to the material. If material is not included in the article's Creative Commons licence and your intended use is not permitted by statutory regulation or exceeds the permitted use, you will need to obtain permission directly from the copyright holder. To view a copy of this licence, visit http://creativecommons.org/licenses/by$\mathrm{nc} / 4.0 /$.

\section{REFERENCES}

1. Guan W, Ni Z, Hu Y, Liang W, Ou C, He J, et al. Clinical characteristics of coronavirus disease 2019 in China. N Engl J Med. 2020;382(18):1708-20.

2. Richardson S, Hirsch JS, Narasimhan M, Crawford JM, McGinn T, Davidson KW, et al. Presenting characteristics, comorbidities, and outcomes among 5700 patients hospitalized with COVID-19 in the New York City area. J Am Med Assoc. 2020;323(20):2052-9.

3. Tordai A, Nagy S, Baróti-Tóth K, Marton I, Lázár M, Demeter J, et al. A SARS-CoV2-járvány hatása a hazai vérellátásra. Hematológia-Transzfuziológia. 2020;53(2):96-105.

4. Chen N, Zhou M, Dong X, Qu J, Gong F, Han Y, et al. Epidemiological and clinical characteristics of 99 cases of 2019 novel coronavirus pneumonia in Wuhan, China: a descriptive study. Lancet. 2020;395(10223):507-13.

5. Wu Z, McGoogan JM. Characteristics of and important lessons from the coronavirus disease 2019 (COVID-19) outbreak in china: summary of a report of 72314 cases from the Chinese center for disease control and prevention. J Am Med Assoc. 2020;323:1239-42 (American Medical Association).

6. Casadevall A, Pirofski LA. The convalescent sera option for containing COVID-19. J Clin Investig. 2020;130(4):1545-8 (American Society for Clinical Investigation).

7. Abraham J. Passive antibody therapy in COVID-19. Nat Rev Immunol. 2020;20:401-3 (Nature Research).

8. Recommendations for Investigational COVID-19 Convalescent Plasma | FDA. https://www.fda.gov/ vaccines-blood-biologics/investigational-new-drugapplications-inds-cber-regulated-products/ recommendations-investigational-covid-19convalescent-plasma

9. Tanne JH. Covid-19: FDA approves use of convalescent plasma to treat critically ill patients. BMJ. 2020;368: m1256.

10. Epstein J, Burnouf T. Points to consider in the preparation and transfusion of COVID-19 convalescent plasma. Vox Sang. 2020;115:485-7 (Blackwell Publishing Ltd).

11. Rojas M, Rodríguez Y, Monsalve DM, Acosta-Ampudia Y, Camacho B, Gallo JE, et al. Convalescent plasma in COVID-19: possible mechanisms of action. Autoimmun Rev. 2020. https://doi.org/10. 1016/j.autrev.2020.102554 (Elsevier B.V.).

12. Simon M, Major B, Vácz G, Kuten O, Hornyák I, Hinsenkamp A, et al. The effects of hyperacute serum on the elements of the human subchondral bone marrow niche. Stem Cells Int. 2018. https:// doi.org/10.1155/2018/4854619.

13. Kardos D, Marschall B, Simon M, Hornyák I, Hinsenkamp A, Kuten $\mathrm{O}$, et al. Investigation of cytokine changes in osteoarthritic knee joint tissues in response to hyperacute serum treatment. Cells. 2019;8(8):824.

14. Li L, Zhang W, Hu Y, Tong X, Zheng S, Yang J, et al. Effect of convalescent plasma therapy on time to clinical improvement in patients with severe and life-threatening COVID-19: a randomized clinical trial. J Am Med Assoc. 2020;324(5):460-70.

15. Agarwal A, Mukherjee A, Kumar G, Chatterjee P, Bhatnagar T, Malhotra P. Convalescent plasma in the management of moderate covid-19 in adults in India: open label phase II multicentre randomised controlled trial (PLACID Trial). BMJ. 2020;22:371.

16. Sostin OV, Rajapakse P, Cruser B, Wakefield D, Cruser D, Petrini J. A matched cohort study of 
convalescent plasma therapy for COVID-19. J Clin Apher. 2021. https://doi.org/10.1002/jca.21888.

17. Simonovich VA, Burgos Pratx LD, Scibona P, Beruto $\mathrm{MV}$, Vallone $\mathrm{MG}$, Vázquez $\mathrm{C}$, et al. A randomized trial of convalescent plasma in COVID-19 severe pneumonia. N Engl J Med. 2021;384(7):619-29.

18. Shenoy AG, Hettinger AZ, Fernandez SJ, Blumenthal J, Baez V. Early mortality benefit with COVID19 convalescent plasma: a matched control study. Br J Haematol. 2021;192(4):706-13.

19. Yoon H, Bartash R, Gendlina I, Rivera J, Nakouzi A, Bortz RH, et al. Treatment of severe COVID-19 with convalescent plasma in Bronx, NYC. JCI Insight. 2021. https://doi.org/10.1172/jci.insight.142270.

20. Salazar E, Christensen PA, Graviss EA, Nguyen DT, Castillo B, Chen J, et al. Treatment of coronavirus disease 2019 patients with convalescent plasma reveals a signal of significantly decreased mortality. Am J Pathol. 2020;190(11):2290-303.

21. Joyner MJ, Senefeld JW, Klassen SA, Mills JR, Johnson PW, Theel ES, et al. Effect of convalescent plasma on mortality among hospitalized patients with COVID-19: initial three-month experience. medRxiv; 2020. p. 2020.08.12.20169359.

22. Duan K, Liu B, Li C, Zhang H, Yu T, Qu J, et al. Effectiveness of convalescent plasma therapy in severe COVID-19 patients. Proc Natl Acad Sci USA. 2020;117(17):9490-6.

23. Xia X, Li K, Wu L, Wang Z, Zhu M, Huang B, et al. Improved clinical symptoms and mortality among patients with severe or critical COVID-19 after convalescent plasma transfusion. Blood. 2020;136: 755-9 (American Society of Hematology).

24. Budhiraja S, Dewan A, Aggarwal R, Singh O, Juneja D, Pathak S, et al. Effectiveness of convalescent plasma in Indian patients with COVID-19. Blood Cells Mol Dis. 2021;1:88.

25. Tworek A, Jaroń K, Uszyńska-Kałuża B, Rydzewski A, Gil R, Deptała A, et al. Convalescent plasma treatment is associated with lower mortality and better outcomes in high-risk COVID-19 patientspropensity-score matched case-control study. Int J Infect Dis. 2021;1(105):209-15.

26. Moniuszko-Malinowska A, Czupryna P, ZarębskaMichaluk D, Tomasiewicz K, Pancewicz S, Rorat M, et al. Convalescent plasma transfusion for the treatment of COVID-19-experience from Poland: a multicenter study. J Clin Med. 2020;10(1):28.

27. Liu STH, Lin HM, Baine I, Wajnberg A, Gumprecht JP, Rahman F, et al. Convalescent plasma treatment of severe COVID-19: a propensity score-matched control study. Nat Med. 2020;26(11):1708-13.

28. Pappa V, Bouchla A, Terpos E, Thomopoulos TP, Rosati M, Stellas D, et al. A phase ii study on the use of convalescent plasma for the treatment of severe covid-19-a propensity score-matched control analysis. Microorganisms. 2021;9(4):806.

29. Klassen SA, Senefeld JW, Johnson PW, Carter RE, Wiggins CC, Shoham S, et al. The effect of convalescent plasma therapy on COVID-19 patient mortality: systematic review and meta-analysis. Mayo Clin Proc. 2021;96(5):1262-75.

30. Libster R, Pérez Marc G, Wappner D, Coviello S, Bianchi A, Braem V, et al. Early high-titer plasma therapy to prevent severe COVID-19 in older adults. N Engl J Med. 2021;384(7):610-8.

31. Janiaud P, Axfors C, Schmitt AM, Gloy V, Ebrahimi F, Hepprich M, et al. Association of convalescent plasma treatment with clinical outcomes in patients with COVID-19: a systematic review and meta-analysis. J Am Med Assoc. 2021;325(12):1185-95.

32. Neubauer M, Kuten O, Stotter C, Kramer K, De LA, Muellner $\mathrm{T}$, et al. The effect of blood-derived products on the chondrogenic and osteogenic differentiation potential of adipose-derived mesenchymal stem cells originated from three different locations. Stem Cells Int. 2019. https://doi.org/10. 1155/2019/1358267.

33. Iglesias Molli AE, Bergonzi MF, Spalvieri MP, Linari MA, Frechtel GD, Cerrone GE. Relationship between the IL-1 $\beta$ serum concentration, mRNA levels and rs16944 genotype in the hyperglycemic normalization of T2D patients. Sci Rep. 2020. https://doi.org/10.1038/s41598-020-66751-x.

34. Arican O, Aral M, Sasmaz S, Ciragil P. Serum levels of TNF- $\alpha$, IFN- $\gamma$, IL-6, IL-8, IL-12, IL-17, and IL-18 in patients with active psoriasis and correlation with disease severity. Mediators Inflamm. 2005;2005(5): 273-9.

35. Katz LM. (A little) clarity on convalescent plasma for COVID-19. N Engl J Med. 2021;384(7):666-8.

36. Pouladzadeh $M$, Safdarian $M$, Eshghi $P$, Abolghasemi H, Bavani AG, Sheibani B, et al. A randomized clinical trial evaluating the immunomodulatory effect of convalescent plasma on COVID-19-related cytokine storm. Intern Emerg Med. 2021. https://doi.org/10.1007/s11739-02102734-8.

37. Bandopadhyay P, Lahiri A, Sarif J, Ray Y, Ranjan Paul S, Roy R, et al. Nature and dimensions of the systemic hyper-inflammation and its attenuation by convalescent plasma in severe COVID-19. 